\title{
Just Improvisation
}

\section{Sara Ramshaw and Paul Stapleton}

\section{Introduction: Law and Improvisation}

One of most common myths or misconceptions surrounding improvisation is that it is structure-less and devoid of "law," adhering to "neither convention nor protocol," tolerating "no system of constraint," and requiring "no prior thought" (Fischlin and Heble 23). In actual fact, improvisation is only made possible through a thorough knowledge of the tradition in which it is taking place, and much practice or dedication is required to learn the skills of the art of improvisation. Why else do many improvisers-John Coltrane being a telling example (Fischlin et al 95)—spend so much time rehearsing for an improvised performance, or preparing to be spontaneous? This work or discipline is "necessary to the extent that it allows the improviser, at the decisive moment, to begin and sustain a work with a degree of certitude that belies the uncertainty of its origin and gestation" (Peters 6).

Critical scholars of improvisation have done much to problematize or criticize the understanding of musical improvisation as unique and unforeseen, as pure spontaneity. Improvisation is not simply "a process of creation that emphasizes freedom" (Panish 123). To improvise well requires an attention to discipline, technical knowledge, as well as "background, history, and culture" (Lewis 153). Rather than eschewing all formality or structure, the improvised act can only be understood in relation to the pre-existent, be it the original melody, theme or musical tradition. In the words of Charles Mingus, "[y]ou gotta improvise on somethin'." To do otherwise would make its recognition as improvisation impossible.

Although improvisation is most often associated with the musical realm, Ramshaw has written extensively about the fundamentally improvisatory nature of the Common Law (see, for example, Ramshaw, Justice). As no two legal actions can be exactly the same, each judicial application of existing rules or past precedents to new facts creates, in fact, a new and improvised law. And it is the very nature of legal judgment that elicits a negotiation between the singularity of a particular case and the pre-existing rules or laws to which it must adhere or follow. Novelty and creativity, however, must be subordinated to tradition and precedent in order for law to remain legitimate and commanding in contemporary society. Law, in other words, cannot be seen to be produced on the spur of the moment. To be just, it must apply fairly and equally and be known by all in advance (Ramshaw, "Jamming" 134; see also, Ramshaw, "Deconstructin(g)" 4).

While not disputing the importance of fairness and equality in relation to law, the collaborative research as between Ramshaw (law) and Stapleton (music) calls for increased recognition of the improvised creativity that is at the heart of justice. One of the key tenets of critical improvisational research is the belief in improvisation's emancipatory promise. Instead of being unplanned and purely spontaneous, improvisation self-consciously engages with tradition and convention, at its best enabling resistance to past oppression and injustice and opening up possibilities for new ways of being together in society, both locally and at the global level.

Ramshaw and Stapleton share an engagement with improvisation as a "social practice" (Heble and Seimerling 42; Fischlin and Heble 11), one that, when applied to both the disciplines of law and music, aims to facilitate new kinds of intercultural and interdisciplinary conversations and foster new, better, ways of being with one another, both as individuals and as members of diverse communities, in multicultural and sometimes divided (as is still the case in Northern Ireland $)^{1}$ societies.

This is, however, no uni-directional application of musical improvisation to the discipline of law. If that were the case, the potential impact would be far less significant. Instead, our interdisciplinary research has the potential to move paradigms underlying research in both fields. Essentially, our collaborative interdisciplinary research is not just about taking knowledge from one discipline and applying it to another. Rather, it is about creating a dialogue that aims to shift established concepts and practices in both disciplines, and thus beyond.

\section{Translating Improvisation Research Group}

This cross-disciplinary dialogue is of crucial importance, as the activities of the Translating Improvisation Research Group evidence. This interdisciplinary research group, led by Ramshaw and Stapleton, originated from Project Group funding from the Queen's University Belfast (QUB) Institute for Collaborative Research in the Humanities (ICRH) during the 2013-14 academic year and, for years to follow, we continued to meet regularly for a seminar series, workshops and concerts. ${ }^{2}$ Translating Improvisation Research Group brings together approximately 30 academics and postgraduate students researching across diverse disciplines, such as architecture, law, anthropology, psychology, drama, dance, and music, to investigate the possibility of bridging the gap between the musical frame for discussion and those in other fields. Our aim is to overcome the popularly held misconception that improvisation is simply "making it up as you go along." Rather, for us, improvisation is more productively understood as a skilled practice that transcends disciplinary boundaries and promotes new approaches to creative decision-making, critical dialogue, risk-taking, and collaboration across diverse domains 
and levels of expertise (for example, how judicial discretion is applied on a case by case basis, or how architectural designs interplay with the agency of builders and inhabitants). We thus endeavour to rethink how best to cope with future events that cannot be predicted with a sufficient level of certainty, or for which a single correct response does not exist. ${ }^{3}$

The Translating Improvisation Research Group highlights the wider challenge of critical improvisation studies. Recent decades have seen a widespread adoption of risk-adverse bureaucracy that has largely failed to deal with the complexities of modern society. What has resulted is the de-professionalization of skilled workers through an over-reliance on targets and procedures. We contend that in many areas of professional practice, no amount of predetermined procedure or technological assistance will successfully replace the ability of a skilful practitioner to adapt to the unique demands and contingencies of individual situations. Therefore, we must better understand how skill is acquired and how expertise can be updated when faced with changing circumstances. Improvisation can provide an alternative model that prioritises human adaptability above inflexible or unenforceable procedures, providing alternative mechanisms for addressing the challenges of specific dynamically unfolding situations. In many areas it is clear that improvisation is the modus operandi even when it is common practice to claim that decisions are entirely directed by procedure, precedent, and other regulatory controls. Therefore, the root of the challenge is not a lack of improvisation, but a significant gap between improvisatory practices and our understanding of how these practices are learned, constrained, and ideally critiqued and reinvented.

\section{Into the Key of Law Research Project}

Building on the collaborative interdisciplinary work of the Translating Improvisation Research Group, in January 2014, Ramshaw and Stapleton were awarded a UK Arts and Humanities Research Council (AHRC) Early Career Research Grant for a project entitled Into the Key of Law: Transposing Musical Improvisation. The Case of Child Protection in Northern Ireland. This project united the fields of Family Law and Critical Studies in Improvisation (CSI), viewing improvisation, as noted above, not just as a musical, but also as a social practice. Improvisation teaches us how to actively listen to the singularity of a situation and its relationship to context and the surrounding circumstances.

Child protection suited this exploration well because of the recent and ongoing review of the system in the UK and the call for a reconsideration of the structures currently in place. Following the Final Report of the Civil and Family Justice Review panel (2011), and the government's response to this report (2012), significant changes were proposed to the organisation and administration of the family courts in England and Wales. Of particular concern was the issue of delay in care proceedings, which can have extremely negative and detrimental effects on children in care.

Contemporaneous to the Civil and Family Justice Review, Professor Eileen Munro was asked by the government to conduct an independent review of child protection in England. The Munro Review of Child Protection: Final Report was published in May 2011, setting out recommendations for the reform of the child protection system, which she viewed as over-bureaucratized and overly concerned with compliance (Munro, Final 5). A childcentered system was recommended, "one that keeps a focus on children, checking whether they are being effectively helped, and adapting when problems are identified" (5). Munro calls for flexibility in decision-making, allowing those working in child protection "to be given more scope to exercise professional judgment in deciding how best to help children and their families" (5).

In her 2012 Progress Report: Moving Towards a Child-Centred System, Professor Munro considered how well the implementation of her recommendations had progressed and "how the child protection landscape as a whole is changing" (Munro, Progress 3). One key recommendation was the removal of fixed timescales, which, on the surface, seemingly contradict the need for swift decision-making in child protection cases. However, in the locations where exemptions were granted from statutory timescales, the results have been very positive, and it is reported that "the additional flexibility has encouraged better, more thoughtful working practices, and better and clearer consideration of priorities" (3).

The Munro Review (and the Progress Report that follows) thereby identified the systematic issue of inferior decisions being made by child protection professionals because too much attention is given to formality (e.g., timescales), without any gain in the sense of this leading to better decisions. In essence, what was being called for is the creation of an adaptive, flexible environment in which improvisation can take place, where improvisation must be understood as the confidence and technical ability to negotiate a smooth path between the demands of the general system of rules and an individual case.

Following Munro, our research project aimed to determine how best to equip legal practitioners, e.g., judges and lawyers, technically and theoretically, to be confident in the improvisatory role that they are being called to undertake. As musicians are perhaps best placed to understand improvisational "language," that is, its techniques, discourses and pedagogies, transposition of knowledge from the musical to the legal realm is not only possible (as is evidenced in this collaboration between a lawyer and a musician), but also necessary. The 
overall aim of the project was therefore to facilitate cross-disciplinary conversation and knowledge transfer on the question of how best to effect better, more creative, and courageous decision-making in the area of child protection law. This, ultimately, impacts not only law and society more generally, but children at risk of abuse and neglect in particular.

The project focused on child protection professionals in the jurisdiction of Northern Ireland (NI). With the recent changes to the family justice system not yet (if at all) applying to the Northern Irish jurisdiction, ${ }^{4}$ the project team was keen to assess how child protection in $\mathrm{NI}$ might differ from other jurisdictions and how innovative solutions developed from this research might also be beneficial elsewhere in the United Kingdom (and beyond).

Through discussions, interviews, and improvisation workshops with key stakeholders in this area, such as judges, lawyers, social workers, policy makers, and charity/third sector employees, along with local and international musicians, this project endeavoured to bring to light further changes necessary to enable quicker, more creative decisions in the area of child protection law and thus to counter inequality and injustice in this area.

This interdisciplinary collaboration brought together a diverse and international research team, consisting of the following:

- $\quad$ Dr Sara Ramshaw (Principal Investigator), lawyer/legal academic (Canada)

- $\quad$ Dr Paul Stapleton (Co-Investigator), musician/improviser/academic (USA)

- Dr Adnan Marquez-Borbon (Postdoctoral Fellow), improviser/musician (Mexico)

- $\quad$ Dr Kathryn McNeilly (Research Assistant), legal academic (Northern Ireland)

- Seamus Mulholland (Research Assistant), Barrister-at-Law (Northern Ireland)

- $\quad$ Dr Matilde Meireles (Research Assistant and Archivist), sound artist (Portugal).

Throughout the life of the project, our research team conducted over thirty (30) semi-structured interviews and five (5) focus groups with musicians and professionals working in the field of child protection, including social workers, policy makers, community activists, as well as prominent members of the Northern Irish judiciary and legal profession, including UK Supreme Court justice and former Lord Chief Justice of Northern Ireland, the Right Honourable the Lord Kerr of Tonaghmore. We also organised and guided six (6) improvisation workshops in which we invited participants from a range of backgrounds and professions to explore the temporal, physical, and social dynamics of improvisation.

\section{Just Improvisation Symposium}

In May 2015, as part of the Into the Key of Law project, we organised an interdisciplinary, international symposium at Queen's University Belfast's Sonic Arts Research Centre (SARC) entitled "Just Improvisation: Enriching Child Protection Law through Musical Techniques, Discourses and Pedagogies." This event brought together academic and non-academic participants, both local and international, from musical, legal, and social work backgrounds to explore the improvised creativity that is at the heart of legal decision-making, specifically as it applies to the area of child protection law.

Over the two days, panel discussions and improvisation workshops explored the current improvisatory practices in the legal domain. Local and international improvising musicians and key members of the Northern Irish judiciary and Bar, such as then Siobhan Keegan QC (Vice Chair of the NI Bar) and Denise McBride QC (now Dame Keegan and Dame McBride, the first Northern Irish High Court judges), alongside Her Honour Judge Patricia Smyth and His Honour Judge Brian Sherrard, discussed the role of improvisatory practices and skills in legal advocacy and judicial decision-making.

Also participating and in attendance were local social workers, social work academics and members of the charity Belfast and Lisburn Women's Aid. They all spoke poignantly about the current issues surrounding Northern Irish child protection law. The symposium was free and open to the public, and included improvisation workshops and a concert by two improvising musicians, Okkyung Lee and Maria Chavez. The keynote speakers included improvising musicians/composers/academics Pauline Oliveros and Ellen Waterman. The ensuing discussions highlighted the importance of improvisation not only as technical ability, but also as one that demands careful listening to and empathy for the multiple parties involved in such delicate and complex cases. ${ }^{5}$

\section{Just Improvisation Special Issue}

This Special Issue is comprised of articles, comments and opinions, and an interview, ensuing from discussions at the "Just Improvisation" Symposium. We are particularly pleased that, before her death in November 2016, Pauline Oliveros agreed to have her keynote address, entitled "Safe to Play," included in this volume. It is a beautiful treatise on the joy of "play": play as improvisation and improvisation as play. She begins by telling us how improvising with babies is one of her favorite things and how, although improvisation cannot be legislated, law, particularly the United Nations Convention on the Rights of the Child (UNCRC), "has helped in many ways to 
promote safety for children and bring consciousness to the value and necessity of safety for children but the child has to feel safe in order to play and to have a healthy life." To an audience of judges, lawyers, social workers, artists and musicians, Oliveros speaks about her revolutionary book, Sonic Meditations, and how it "seems to resonate with the principles of the UNCRC." She concludes with two thirty-second listening meditations, during which the environment is enlivened through what Oliveros describes as "the listening effect." Following this sequence of near silent contemplation, Oliveros leaves us with one final question: "Can we make our listening a safe zone, a place where the children of the world will feel safe to play?"6

In the wake of Pauline's untimely passing, her longtime spouse and collaborator, IONE, a writer and performance artist, very kindly agreed to share her thoughts about her and Pauline's time in Belfast. In a piece called "Listening with Pauline in Belfast," she writes about the "joy" she, Maria Chavez, and Pauline all felt, celebrating their birthdays together at the symposium. And about the curiosity felt by the participants—child and family advocates (judges, lawyers, and therapists) and artists and musicians of all kinds-all being in the same room together, discussing the difficult topic of child protection. She writes: "We had all experienced our own families. Most importantly, we had all been children" (emphasis in original). IONE's piece captures the transformative potential of interdisciplinary conversations and the importance of listening-really listening-to one another. As is poignantly articulated in her final sentence: "Here, it was 'safe to play."'

We are also very grateful to have from the keynote speaker, Ellen Waterman, "Notes on Improvisation and Justice," which she wrote up immediately following the event. She writes about how she came to the symposium thinking "the goal was to examine the ways that improvisers can inform child protection law." She left with "the insight that those involved in child protection law are themselves practiced improvisers in a field where the stakes are the lives, health, and welfare of children and women suffering from domestic abuse." In her description of the two days, Waterman shares with us her thoughts as to the power and possibility of interdisciplinary interactions as between improvising musicians and those working in the area of child protection law.

Another participant in the symposium, Simon Rose, begins his essay, "When law listens," with an image of the river: "its two distant banks and the separated practices of law and improvisation in music." He then proceeds to deconstruct or challenge this supposed separateness, illustrating the profound significance of interdisciplinary conversation for all those involved in law and music. Rose focuses his reflection on the final panel of the conference, a panel that included two judges and a barrister (who would soon become one of Nl's first female High Court judges). These speakers spoke of the challenges they faced in relation to child protection law, but also the need for creativity and "bespoke solutions," because every child, every family, is different. Rose reveals how working with difference is "a forte of improvisation," thereby highlighting instances of unity between the two fields. He also engages with improvisation's concern with the changing circumstances found in the present and creative response, and how awareness of this critically informs judicial decision-making in child protection law. Finally, the "myriad out-workings" of trials, which work to surprise even the most seasoned lawyer, is thought through by Rose as a call for the acknowledgement of the improvisational in the judicial process. Conversely, these "myriad out-workings" also offer an interdisciplinary and novel "articulation for improvisation in music practice." Rose ends his piece with law and music both "standing on the same bank."

Bennett Hogg's article, "Improvisation in Process," highlights the shared practices and concerns of improvisation and social justice. More than the other papers, though, he is attentive to their dissimilarities and distinctions. As he writes: "Structural similarities are not enough: improvisation and judgment are not abstractions to be mapped onto one another, but concrete cultural practices. Apparent similarities, then, should not be carelessly accepted as de facto connections, but should initiate deeper interrogation of the phenomena under investigation." This "deeper interrogation" illustrates, for example, that while "[j]udgments affected by racial, class, or gender stereotypes can destroy lives, . . . few lives are ruined by music improvisation." This is an important point and one that Ramshaw has written about elsewhere (see Ramshaw, "The Creative Life"; "Improvising (II)legality"). After a careful and thoughtful discussion of the "musical work," what it means to be "heard," and the role of "mediation" in both music and law, Hogg concludes that, although we cannot "transpose practices from musical improvisation onto the judicial process," we can "allow insights from the former to inform emergent strategies in the latter." This article offers a stimulating reading of the relationship between law and musical improvisation, especially for those interested in this area of interdisciplinary research.

Simon Waters, a member of the Translating Improvisation Research Group at QUB and important contributor to its activities and those of the Into the Key of Law research project, provides a meditation on the "ethics of listening" from an improvising musician's perspective. Bringing together seemingly disparate topics-from Billy Elliot's description of dancing as "disappearance" in his audition for the Royal Ballet in the film by Stephen Daldry to Sartre and de Beauvoir's descriptions of sexual activity and the erotic, as described by Penelope DeutscherWaters skilfully paints the "self (body)" as "an ethical relation with otherness" in which empathy becomes an improvisatory strategy of "'othering the self' through the relinquishing of familiar assumptions that 'control' or 'exploration' must always be conscious, attentive conduct." Although room does not exist in this editorial to summarise adequately the richness of Waters' argument, we will end as he does, noting that, for anyone interested in issues of ethics and justice, it must be realised that the "empathic body is also necessarily an improvising body." 
Kathryn McNeilly and Paul Stapleton's article, "Judging the Singular: Towards a Contingent Practice of Improvisation in Law," explores the benefits of improvisation in relation to judicial decision-making and calls for a more "conscious and critical practice" of improvisation in law. The authors encourage judges, and the legal system as a whole, to consciously think of the judicial role in improvisational terms, engaging in what the authors call, "judging the singular." This activity of judging singularity involves "a contingent approach to and practice of improvisation in law; one that is grounded in the context within which it takes place and is inherently open to responsive development and change based upon this context." Applying empirical research gathered from the Into the Key of Law research project, McNeilly and Stapleton structure their discussion around certain key themes, which emerged from interviews with judges, lawyers, social workers, and improvising musicians, namely those of "singularity," "anticipation," "responsiveness/adaptability," and "constraint." What emerges from this research is a portrait of judges as always already expert improvisers in everyday decision-making. However, this expertise is constrained by various institutional factors, such as "trends towards a marginalization of singularity, limited space for effective and holistic listening, responsiveness and adaptability as well as an advancement of bureaucracy over expertise." The authors ultimately conclude that even within a highly constrained legal system, judges and other legal professionals can-and often must-adapt, and that such improvisational expertise should be made more visible as "something that needs to be developed, fostered, and practiced, just like any other skill."

The article by Ramshaw, Marquez-Borbon, Mulholland, and Stapleton, entitled "Hydra: A Creative Training Tool for Critical Legal Advocacy and Ethics," details the development and aims, as well as the key tenets, of the improvisational "game piece," Hydra, ${ }^{7}$ which was invented by the Into the Key of Law research team, with the input of participants in the initial pilot and discussions with focus group and audience members at various international conferences and events. Hydra is a response to perceived deficiencies in traditional moot court or advocacy training in common law legal education, which is often criticised for failing to adequately prepare advocates to be nimble-footed in the courtroom and able to respond quickly and responsively to unexpected situations or the needs of their clients. In contrast, Hydra, named after the serpent-like water monster with numerous heads in Greek mythology, hones legal argumentation skills, requiring participants to be Hydra-headed and skilled at rapidly analysing a legal issue from a variety of angles and perspectives, teaching advocates to be prepared for the unexpected. This article focuses on the importance of moulding creative, critical, and ethical legal advocates and how improvisation can be used as a pedagogical tool or practice to inspire such creativity, openness and empathy. In the final section, the authors outline the components or "rules" of Hydra and the deficiencies they think this game piece will address in legal education.

The final contribution to the Special Issue is an interview with Her Honour Judge Patricia Smyth of the Northern Ireland County Court, who the authors, perhaps slightly provocatively, label "The Improvising Judge" (it ends up, she loves it!). Judge Smyth was an invaluable contributor to the Into the Key of Law research project, volunteering as a project interviewee, focus group member and a panel participant at the "Just Improvisation" Symposium. Generously giving up her time to consent to this interview, Judge Smyth provides valuable insight into a variety of important issues, such as training judges to become better improvisers, the limits of improvisation in, particularly, Northern Irish family law, the existing structures or skills that make improvisation possible and, perhaps most importantly, the importance of creativity, "bespoke solutions" (her words), and attentive or deep listening in the family law realm.

In addition to the pieces which comprise Just Improvisation, this issue also features two general topics articles. The first, "Improvising New Realities: Movement, Sound and Social Therapeutics," by Sandra Paola López Ramírez and Christopher Eric Reyman, focuses on dance and music improvisation, exploring the parallels between these practices and social therapeutics. Drawing on the growth and development of the communitybased work of in2improv, the paper frames the experience of performance and improvisation as powerful tools for social transformation, which the authors have adapted to empower underserved communities. The second, "Improvisation et Parrêsia: Des pratiques politiques de soi" by Fabien Granjon, presents the work of Bernard Lubat and fellow musicians in the town of Uzeste (France), where they have developed a form of experimental artistic practice, rooted in regional social and political history. Granjon analyses this practice as a form of Parrêsia (Foucault), holding to the sphere of personal ethics yet not unrelated to a deindividualized political practice. Also included in this issue is a notes and opinions piece by Paddy Gordon, which combines personal reflection and theory to report on two community music projects grounded in improvisation and deep listening that took place in Melbourne, Australia, in 2016, as well as five book reviews.

The editors of this Special Issue wish to thank the Arts and Humanities Research Council (AHRC) in the UK for funding the interdisciplinary research project, Into the Key of Law: Transposing Musical Improvisation. The Case of Child Protection in Northern Ireland. We would also like to thank QUB's Institute for Collaborative Research in the Humanities (ICRH), which, sadly, no longer exists, and QUB's Sonic Arts Research Centre (SARC) and School of Law, which provided both financial and other support.

As one final thought, we dedicate this Special Issue to composer, improviser, and humanitarian Pauline Oliveros, who died on 24 November 2016 at her home in Kingston, NY, at the age of 84. Pauline was a remarkable human being and a phenomenal and gifted artist. She will be dearly missed_-but never forgotten. ${ }^{8}$ 


\section{Notes}

1 The focus on Northern Ireland (NI) stems from the fact that the editors of this collection were, and one still is (Stapleton), resident in $\mathrm{NI}$ for at least a decade. Much of the research discussed in this editorial is also focused on NI. In terms of the division that still exists in the jurisdiction, despite the Belfast (or Good Friday) Agreement 1998 establishing a power-sharing executive framework, NI remains in crisis. For more information on the crisis and division in $\mathrm{NI}$ as it relates to improvisation, see Ramshaw and Stapleton (forthcoming).

${ }^{2}$ We meet less regularly now that Ramshaw is based in Canada, but ad hoc events continue.

${ }^{3}$ Recordings of the seminar series and other related events are all available via our Translating Improvisation website, http://www.translatingimprovisation.com/archive.

${ }^{4}$ Northern Ireland is currently in the process of reviewing the family justice system to assess and improve current procedures. The Final Report of the Civil and Family Justice Review Group was published in September 2017 and can be found at https://www.judiciary-ni.gov.uk/sites/judiciary-ni.gov.uk/files/mediafiles/Family\%20Justice\%20Report\%20September\%202017.pdf. For more information, see https://www.judiciaryni.gov.uk/civil-and-family-justice-review.

${ }^{5}$ Documentation of the symposium is available via the Translating Improvisation website, http://www.translatingimprovisation.com/portfolio/symposium.

${ }^{6}$ A recording of Oliveros's keynote address is available on Translating Improvisation website, www.translatingimprovisation.com and on Vimeo http://www.vimeo.com/130415308.

${ }^{7}$ As is detailed in the paper by Ramshaw, Marquez-Borbon, Mulholland, and Stapleton, Hydra owes its inspiration to John Zorn's Cobra.

${ }^{8}$ For those unfamiliar with her work, see the Deep Listening Institute website, http://deeplistening.org/site/content/home, and the Pauline Oliveros website, http://paulineoliveros.us. For further information on Pauline and her career, see, for example, tributes in The New York Times (Smith) and The New Yorker (O’Brien).

\section{Works Cited}

Civil and Family Justice Review Group (Northern Ireland). Review Group's Report on Family Justice. Office of the Lord Chief Justice, 2017. https://www.judiciary-ni.gov.uk/sites/judiciary-ni.gov.uk/files/mediafiles/Family\%20Justice\%20Report\%20September\%202017.pdf.

Fischlin, Daniel and Ajay Heble. "The Other Side of Nowhere: Jazz, Improvisation, and Communities in Dialogue." The Other Side of Nowhere: Jazz, Improvisation, and Communities in Dialogue. Edited by Daniel Fischlin and Ajay Heble, Wesleyan UP, 2004, pp. 1-42.

Fischlin, Daniel, Ajay Heble, and George Lipsitz. The Fierce Urgency of Now: Improvisation, Rights, and the Ethics of Cocreation. Duke UP, 2013.

Lewis, George. "Improvised Music after 1950: Afrological and Eurological Perspectives." The Other Side of Nowhere: Jazz, Improvisation, and Communities in Dialogue. Edited by Daniel Fischlin and Ajay Heble, Wesleyan UP, 2004, pp. 131-62.

Heble, Ajay and Winfried Seimerling. "Voicing the Unforeseeable: Improvisation, Social Practise, Collaborative

Research." Cross-Talk: Canadian and Global Imaginaries in Dialogue. Edited by Diana Brydon and Marta Dvořák, Wilfred Laurier UP, 2012.

Munro, E. The Munro Review of Child Protection: Final Report. A Child-Centred System. The Stationary Office, 2011.

---. Progress Report: Moving Towards a Child-Centred System. The Stationary Office, 2012. 
O’Brien, Kerry. "Listening as Activism: The 'Sonic Meditations' of Pauline Oliveros." New Yorker 9 December 2016, https://www.newyorker.com/culture/culture-desk/listening-as-activism-the-sonic-meditations-ofpauline-oliveros.

Panish, Jon. The Color of Jazz: Race and Representation in Postwar American Culture. UP Mississippi, 1997.

Peters, Gary. "Certainty, Contingency, and Improvisation." Critical Studies in Improvisation / Études critiques en improvisation vol. 8, no. 2, 2012, www.criticalimprov.com/article/view/2141/2900.

Ramshaw, Sara. Justice as Improvisation: The Law of the Extempore. Routledge, 2013.

---. "Improvising (II)legality: Justice and the Irish Diaspora, NYC, 1930-1932." Irish Journal of Legal Studies vol 3 , no. 1,2013 , pp. 90-121.

---. "The Creative Life of Law: Improvisation, Between Tradition and Suspicion." Critical Studies in Improvisation / Études critiques en improvisation vol. 6 no. 1, 2010, http://www.criticalimprov.com/article/view/1084.

---. "Jamming the Law: Improvised Theatre and the "Spontaneity' of Judgment" Law Text Culture vol. 14, 2010, pp. 133-59.

---. "Deconstructin(g) Jazz Improvisation: Derrida and the Law of the Singular Event." Critical Studies in Improvisation / Études critiques en improvisation vol. 2 no. 1, 2006, http://www.criticalimprov.com/article/view/81/188.

Ramshaw, Sara and Paul Stapleton. "From Pre-Peace to Post-Conflict: The Ethics of (Non-) Listening and Cocreation in a Divided Society." Sound Changes: Improvisation, Social Practice, and Cultural Difference, Volume Two. Edited by Daniel Fischlin and Eric Porter, Duke UP, forthcoming.

Smith, Steve. "Pauline Oliveros, Composer Who Championed 'Deep Listening', Dies at 84." New York Times 27 November 2017, https://www.nytimes.com/2016/11/27/arts/music/pauline-oliveros-composer-whochampioned-deep-listening-dies-at-84.html?mcubz=0. 